\title{
Enade: os estudantes estão motivados a fazê-lo?
}

\section{Resumo \\ Objetivo: Tendo por bases os pressupostos das abordagens teóricas sociocognitivistas, este estudo teve o propósito de identificar os níveis de motivação dos estudantes de Ciências Contábeis para a realização do Enade, com e sem a oferta de mecanismos de motivação extrínseca. A pesquisa é de natureza descritiva, com abordagem quantitativa, realizada por meio de um levantamento feito com 1.082 estudantes de 122 instituições brasileiras.}

Método: Trata-se de uma pesquisa descritiva, com abordagem quantitativa, realizada por meio de um levantamento. Para testar se existiam diferenças significativas entre os níveis de motivação discente, com e sem a oferta de mecanismos de motivação para a realização do Enade, foram utilizados os testes não paramétricos Mann-Whitney e Wilcoxon.

Resultados: Foi constatado que os níveis de motivação dos estudantes investigados para realizarem o Enade 2015 são estatisticamente inferiores à motivação que eles têm para fazer o curso de Ciências Contábeis. Os resultados apontaram que a oferta de estímulos, sejam eles registro da nota no diploma; uso da nota para ingresso em pós-graduação; uso da nota para concursos públicos ou para o exame do CFC, como recompensa a esses estudantes, afeta positivamente a intenção (motivação) para a realização do Enade.

Contribuições: Considerando que o Enade vem se consolidando como uma avaliação em larga escala no Brasil, ajustes que ajudem a tornar o sistema mais acurado são importantes. Os achados da presente pesquisa sugerem que o uso da nota Enade dos alunos em etapas posteriores à carreira universitária poderá servir como estímulo para que se dediquem mais à avaliação, reduzindo a resistência, os "boicotes" e tornando os resultados do exame mais precisos, especialmente no curso de Ciências Contábeis, que é o quarto em quantidade de matrículas no Brasil, e pelo fato de que os discentes estão sujeitos a outra avaliação para o exercício da profissão, o Exame de Suficiência. Palavras-chave: Sinaes, Enade, Ciências Contábeis, Motivação.

\section{Gilberto José Miranda \\ https://orcid.org/0000-0002-1543-611X Doutor em Controladoria e Contabilidade pela Universidade de São Paulo (USP) e Professor na Universidade Federal de Uberlândia (UFU). Contato: Av. João Naves de Avila, 2121, bloco F, sala 1F253, Santa Mônica, Uberlândia (MG), CEP: 38.408-902. E-mail: gilbertojm@ufu.br}

\section{Edvalda Araújo Leal}

https://orcid.org/0000-0002-7497-5949

Doutora em Administração pela Fundação Getúlio Vargas (FGV/SP) e Professora na Universidade Federal de Uberlândia (UFU). Contato: Av. João Naves de Avila, 2121, bloco F, sala 1F253, Santa Mônica, Uberlândia (MG), CEP: 38.408-902. E-mail: edvalda@ufu.br

\section{Mônica Aparecida Ferreira} https://orcid.org/0000-0003-3771-1933 Mestre em Ciências Contábeis pela Universidade Federal de Uberlândia (UFU). Contato: Av. João Naves de Avila, 2121, bloco F, sala 1F253, Santa Mônica, Uberlândia (MG), CEP: 38.408-902. E-mail: monicaapferreira@hotmail.com

\section{Aline Barbosa de Miranda https://orcid.org/0000-0002-8313-747X Doutora em Educação pela Universidade São Paulo (USP) e Professora na Prefeitura Municipal de Uberlândia (PMU). Contato: Av. João Naves de Avila, 2121, bloco F, sala 1F253, Santa Mônica, Uberlândia (MG), CEP: 38.408-902. \\ E-mail: alinebarbosas@yahoo.com.br}




\section{Introdução}

O relatório Education at a Glance 2015, elaborado pela Organisation for Economic Co-operation and Development (2015), evidencia importantes avanços na educação brasileira nos últimos anos. O maior percentual do Produto Interno Bruto (PIB) investido nos diversos níveis e modalidades de ensino e o consequente aumento de vagas é um exemplo. Todavia, o referido relatório também destaca relevantes problemas a serem superados. Entre os países analisados, o Brasil apresenta o maior percentual (76\%) de jovens de 20 a 24 fora dos bancos escolares, sendo que $20 \%$ dos jovens, além de não estudarem, também não trabalham.

$\mathrm{Na}$ mesma direção, o último Censo Nacional da Educação Superior, divulgado pelo Instituto Nacional de Estudos e Pesquisas Educacionais Anísio Teixeira (2016), aponta avanços significativos na expansão de vagas ofertadas no ensino superior no Brasil na última década. O número de matrículas no ensino superior saltou de 3.887.022, em 2003, para 8.033.574, em 2015, representando um crescimento de praticamente $107 \%$ em pouco mais de uma década. Dentre os cursos mais concorridos, nas modalidades "presencial" e "a distância", destaca-se o curso de Ciências Contábeis, que ocupa a quarta posição, logo atrás dos cursos de Direito, Administração e Pedagogia, com 4,5\% das matrículas no ensino superior registradas no ano de 2015.

O crescimento experimentado pelo ensino superior brasileiro, embora seja muito importante, ainda representa pouco diante da posição ocupada pelo país quando comparado a outras nações. Além disso, para a consolidação de um ensino superior dentro dos parâmetros desejáveis no Brasil, é importante que o crescimento ocorra com qualidade, em outras palavras, são necessárias mais vagas, mas também condições de permanência e conclusão do curso. Desse modo, é necessário que a evolução quantitativa seja adequadamente monitorada por um sistema de avaliação capaz de mensurar os elementos destacados pelos especialistas do MEC, tais como: o ensino, as instituições e os docentes.

Para tanto, alguns programas de avaliação da educação superior vêm sendo experimentados desde a década de 1990 no Brasil, como: Provão (também conhecido como ENC) e o Sistema Nacional de Avaliação do Ensino Superior (Sinaes). O sistema vigente é o Sinaes, cujo propósito é exatamente avaliar alunos, professores e instituições. Entre as críticas que se apresentam ao sistema, está o fato de não haver estímulos que motivem os estudantes a explorarem toda a sua capacidade durante as avaliações, pois as notas desses alunos não são divulgadas nem utilizadas por eles para outras finalidades.

A lei que regulamenta o Sinaes prevê alguns benefícios para os alunos com melhor desempenho, todavia, essas possíveis "premiações" não são amplamente divulgadas, na realidade são desconhecidas pela maioria dos discentes e docentes. Essas fragilidades contribuem para que, em alguns casos, as notas obtidas pelas instituições não representem precisamente o desempenho de seus alunos. A esse respeito, alguns estudos evidenciam possibilidades de boicotes e desinteresse por parte dos estudantes (Leitão, Moriconi, Abrão \& Silva, 2010; Borges, Silva \& Miranda, 2015). Os boicotes não representam, necessariamente, atitudes extremas, como o não comparecimento ao local de provas - pois isso poderia resultar em sansões a que alunos e instituições de ensino superior estão sujeitos - mas a não realização da avaliação com o necessário estímulo que possibilite mensurar as habilidades e conhecimentos reais dos discentes.

Considerando-se a importância da avaliação, os baixos níveis de motivação dos participantes poderiam tornar menos precisos os resultados do exame, o que seria prejudicial às instituições de ensino e ao próprio Sinaes. Nesse contexto, o curso de Ciências Contábeis também se destaca, mas de forma negativa, pois o curso vem figurando entre os últimos colocados desde a primeira edição, que ocorreu em 2006, com notas médias na prova Enade (conhecimentos específicos e gerais) em torno de 37\%. 
Com o intuito de tornar as avaliações mais acuradas e, consequentemente, fortalecer o Sinaes, torna-se importante a busca por formas de motivar os estudantes para a realização do Exame Nacional de Desempenho de Estudantes. Para tal propósito, as abordagens sociocognitivistas, que têm suas raízes nas teorias comportamentais, estabelecem a existência de duas orientações motivacionais que poderão contribuir para a compreensão dos mecanismos que possivelmente evidenciam os fatores que estimulam os discentes a realizarem a avaliação de forma motivada: a) motivação intrínseca: quando o estudante estuda porque gosta da atividade em si mesma, não está submetido a pressões e seu estímulo tem origem em necessidades inerentes à própria pessoa; b) motivação extrínseca: quando o aluno estuda para alcançar algo externo ou evitar punições, almeja alcançar efeitos desejáveis ou evitar os indesejáveis (Amabile, Hill, Hennessey \& Tighe, 1994; Harackiewicks \& Elliot, 1993; Mandelink \& Harackiewicz, 1984). Estudos sobre motivação realizados em cursos de Ciências Contábeis no Brasil têm evidenciado que os estudantes são sensíveis a mecanismos de motivação extrínseca (Leal, Miranda \& Carmo, 2013).

Diante do exposto, identifica-se uma lacuna importante a ser investigada: a possibilidade de uso dos resultados do Enade em etapas posteriores à carreira dos estudantes alteraria os níveis de motivação para a realização da avaliação?

O objetivo geral da pesquisa consiste em identificar os níveis de motivação dos estudantes de Ciências Contábeis para a realização do Enade com e sem a oferta de estímulos motivacionais. Os objetivos específicos são: (a) identificar os níveis de motivação dos alunos para realização do curso de Ciências Contábeis; (b) identificar os níveis de motivação dos alunos para realização do Exame Nacional do Ensino Médio (Enem) (aqueles que fizeram) e para a realização do ENADE 2015; (c) identificar os níveis de motivação mediante a oferta de mecanismos de motivação extrínsecos para a realização do Enade; (d) confrontar os referidos níveis de motivação; (e) avaliar se, na percepção dos alunos pesquisados, esta pesquisa poderia afetar seus níveis motivacionais para a realização do Enade 2015.

\section{Sistemas de Avaliação do Ensino Superior no Brasil}

O processo de avaliação está presente no sistema educacional há algum tempo e faz parte de diversos sistemas educacionais em diferentes países. Freitas e Cornacchione (2015) ressaltam que o tema "avaliação" está presente nas instituições seja para mensurar o processo de aprendizado dos discentes, seja para aferir as condições de seu ensino. Para Dias Sobrinho (2010), a avaliação consiste em uma ferramenta importante para otimizar o processo de organização e implementação das reformas educacionais. $\mathrm{O}$ autor ressalta que o sistema de avaliação produz "mudanças nos currículos, nas metodologias de ensino, nos conceitos e práticas de formação, na gestão, nas estruturas de poder, nos modelos institucionais, nas configurações do sistema educativo, nas políticas e prioridades da pesquisa, nas noções de pertinência e responsabilidade social" (p. 195).

A partir dessa afirmação, percebe-se que a avaliação não só analisa o sistema educacional, mas também orienta comportamentos, seja das instituições de ensino, para que se adéquem à maneira como são avaliadas; seja de outros agentes envolvidos nesse processo, como coordenadores de curso, professores e alunos. Nesse sentido, Melo, Nunes e Michels (2012, p. 857) ressaltam que "a avaliação é vista com resistência pelos diversos segmentos da comunidade acadêmica das instituições de educação superior brasileiras".

Ao analisar a evolução dos sistemas de avaliação do ensino superior no Brasil, percebe-se que ocorreu, pela primeira vez, em 1970, realizada pela Capes nos cursos de mestrado e doutorado. Nos cursos de graduação, um pouco mais tarde, ocorreram algumas tentativas de regulamentação, tais como: o Programa de Avaliação da Reforma Universitária (Paru) no período de 1983 a 1984; a Comissão de Notáveis e Grupo Executivo da Reforma da Educação Superior (Geres), que durou de 1985 a 1986; houve uma "Experiência da autoavaliação" das Instituições entre os anos 1987 a 1992; e, em 1993, iniciou-se o Programa de Avaliação Institucional das Universidades Brasileiras (Paiub), (Polidori, Marinho-Araújo \& Barreyro, 2006). 
Para Santos (2012), os primeiros instrumentos de avaliação do ensino superior efetivos, no nível de graduação no Brasil, começaram no Governo de Fernando Henrique Cardoso, no ano de 1995, com a criação da Lei n. ${ }^{\circ}$ 9.131/1995, que vigorou de 1995 a 2002. Com essa lei foi instituído o Exame Nacional de Cursos (ENC), mais conhecido como Provão. A lei determinava que o ENC-Provão fosse aplicado anualmente e deveria contemplar os conteúdos mínimos, com o objetivo de verificar competências, habilidades e conteúdos essenciais adquiridos pelos egressos do ensino superior, respeitando as especificidades de cada área do conhecimento. Era de competência do Ministério da Educação (MEC) a divulgação do conceito obtido pelo aluno nos meios de comunicação e registro no histórico escolar do estudante (Santos, 2012).

O ENC-Provão vigorou até 2003, quando o Governo do então presidente Luiz Inácio Lula da Silva instituiu o Sistema Nacional de Avaliação da Educação Superior (Sinaes) (Santos, 2012). O aparato legal que regulamenta o Sinaes está na Lei n. ${ }^{\circ}$ 10.861, de 14 de abril de 2004. De acordo com esse dispositivo, a avaliação dos estudantes é realizada mediante a aplicação do Exame Nacional de Desempenho de Estudantes (Enade).

A Lei n. ${ }^{\circ} 10.681$, de 2004, prescreve que a referida avaliação assume o papel de componente curricular obrigatório nos cursos de graduação. No histórico escolar do estudante, é inscrita "somente" a sua situação regular com relação a essa "obrigação", atestada pela sua efetiva participação ou dispensa oficial pelo Ministério da Educação, na forma estabelecida em regulamento.

A responsabilidade de inscrição dos alunos habilitados a fazerem o Enade do INEP é do dirigente da instituição de ensino superior. O não cumprimento dessa determinação incide em sansões previstas no $₫ 2^{\circ}$ do Art. 10 da Lei n. ${ }^{\circ} 10.681$, de 2004. Os resultados insatisfatórios deverão ser submetidos a um protocolo de compromisso, firmado entre a instituição de ensino superior e o MEC. O descumprimento desse protocolo, no todo ou em partes, poderá ensejar nas seguintes penalidades mencionadas no parágrafo 2: I - suspensão temporária da abertura de processo seletivo de cursos de graduação; II - cassação da autorização de funcionamento da instituição de educação superior ou do reconhecimento de cursos por ela oferecidos; III - advertência, suspensão ou perda de mandato do dirigente responsável pela ação não executada, no caso de instituições públicas de ensino superior.

A Lei que regulamenta o Sinaes e, por conseguinte, o Enade, não prevê apenas sansões e penalidades, mas também benefícios para alunos com bom desempenho. De acordo com o $\$ 10$ do Art. 5, o Ministério da Educação concederá estímulos aos estudantes de melhor desempenho no Enade na forma de bolsa de estudos, ou auxílio específico, ou ainda alguma outra forma de distinção com objetivo similar, destinado a favorecer a excelência e a continuidade dos estudos, em nível de graduação ou de pós-graduação, conforme estabelecido em regulamento.

Cabe ressaltar que o Enade sofreu alterações ao longo dos anos, se comparado à forma como foi originalmente criado. Por exemplo, em 2009, o exame passou a ser populacional e não amostral (como era inicialmente) e, em 2011, deixou de ser aplicado a ingressantes e passou a ser aplicado apenas aos concluintes (Brito, 2015).

A literatura sobre os sistemas de avaliação no Brasil aponta algumas ponderações a respeito. Para Polidoro, Marinho-Araújo e Barreyro (2006), trata-se de um sistema complexo, haja vista a diversidade de cursos avaliados e a extensão territorial brasileira. Nesse sentido, o desafio consiste em alinhar as necessidades regulatórias à cultura de avaliação das instituições. Para Dias Sobrinho (2008):

Em um contexto de explosão quantitativa dos sistemas superiores e das múltiplas demandas sociais, os diferentes atores disputam os papéis que caberiam à educação superior frente ao Estado, à sociedade, ao mercado, à comunidade educativa, aos "clientes", ao setor produtivo, bem como os diversos tipos de serviço que as instituições devem oferecer. (Dias Sobrinho, 2008, p. 1) 
Para o autor, o Sinaes "está deixando de ser uma produção de significados, questionamento sobre a pertinência e a relevância científica e social da formação e dos conhecimentos, e passando a reduzir-se à medida e ao controle" (Dias Sobrinho, 2008, p. 5). Em outras palavras, o sistema estaria se reduzindo a índices. Compartilhando dessa visão, Brito (2008) afirma que, na maioria das vezes, esses indicadores são utilizados para alocação de recursos e para tornar pública uma imagem da instituição, no entanto eles não contribuem efetivamente para a melhoria das IES.

Dias Sobrinho (2008) ressalta ainda que o sistema está se resumindo à análise de desempenho estudantil (medido por meio do Enade), que resulta em classificações e rankings entre as instituições, no entanto a análise de qualidade dos cursos e das instituições é muito mais que isso. Ainda, segundo o autor, "não há teoria educacional que sustente que o desempenho de um estudante em uma prova seja plena garantia de aprendizagem, nem de que o resultado de um conjunto de estudantes num exame seja igual à qualidade de um curso" (p. 6), notadamente quando os estudantes não possuem motivações para a realização desses exames.

Outra crítica trazida por Dias Sobrinho (2008) diz respeito às atividades de docência e à pesquisa:

O INEP pergunta, por exemplo, se há plano de curso, mas não põe em discussão os significados desse plano de curso, se está adequado à missão institucional, se é bem desenvolvido, se corresponde às necessidades da sociedade e em que concepção ético-política se inscreve, que tipo de formação propicia, etc. Pergunta se há laboratórios, mas sem distinguir a importância relativa e a pertinência de um laboratório para cada curso em particular (por exemplo, engenharia e filosofia, requerem insumos diferentes) (Dias Sobrinho, 2008, p.822).

Tudo isso gera uma inversão de papéis, de forma que não são mais os professores e pesquisadores que determinam as políticas educacionais dentro da instituição, mas, sim, os agentes externos à realidade da instituição, por meio dos sistemas de avaliação (Dias Sobrinho, 2008).

Mesmo com críticas, o Enade parece ser um indicador válido, pois, segundo Hanushek (2002), a aplicação de testes padronizados é um dos meios mais utilizados para mensurar a qualidade do ensino. Entretanto, segundo Leitão et al. (2010), por vezes, o exame é contestado por alunos e por instituições. Os autores afirmam que, em diversos momentos, veem-se relatos de alunos na mídia afirmando ser injusto o peso dado ao aluno na realização do exame, já que o objetivo final é avaliar o curso e não propriamente o aluno. Ressaltam ainda que inúmeras instituições reclamam que os alunos não possuem incentivos para comprometer-se com o Enade, o que acaba por afetar o resultado dos cursos e das instituições. Cabe ressaltar que a prova do Enade além de avaliar conhecimentos gerais e específicos relacionados à área de formação, em seu questionário socioeconômico abrange questões relativas à instituição, como infraestrutura, organização pedagógica, formação docente, dentre outros fatores que também são determinantes no desempenho acadêmico.

Para Leitão et al. (2010), a aplicação de exames nacionalmente gera discussões a respeito da provável falta de envolvimento e resistência dos alunos no processo avaliativo. Os autores apresentam duas categorias diferentes de boicote: a primeira engloba aqueles alunos que colam adesivos ou fazem qualquer tipo de registro explícito, que demonstrem posição contrária ao exame. A outra categoria engloba aqueles que não respondem a nenhuma questão na prova, entregam a avaliação em branco. Em ambos os casos, os alunos comparecem à prova, no entanto não a realizam conforme o esperado.

A ausência no dia da prova poderia ser considerada uma possibilidade de boicote. No entanto, ao analisar o caráter obrigatório e a punição a que o aluno está sujeito, caso não compareça (não emissão do diploma), não seria viável boicotar dessa forma. E ainda seria difícil segregar a causa da ausência, se seria boicote ou se realmente o aluno não pôde comparecer a avaliação por outros motivos (Leitão et al., 2010).

Leitão et al. (2010) também constataram que os alunos "boicotantes" em geral apresentam renda familiar mais alta, pais mais escolarizados e cursaram maior parte do ensino médio em escolas privadas, além disso tendem a avaliar negativamente aspectos relacionados à instituição (estrutura física e aspectos pedagógicos), o que pode indicar que, por vezes, o aluno boicota o ENADE para demonstrar sua insatisfação com o curso ou com a instituição. 
Pederneiras, Lopes, Ribeiro Filho e Feitosa (2011) analisam a participação dos alunos no Enade sob outra perspectiva. Os autores levantam a hipótese de que o resultado desse exame pode ser influenciado por três fatores: sensibilização, motivação e compromisso. Nesse estudo, os autores constataram que os entrevistados (líderes e gestores) relataram que os alunos não são motivados a realizarem o Enade e só vão por serem obrigados a participarem, pois, caso contrário, não recebem seu diploma. Os entrevistados ainda ressaltaram que deveria haver incentivo para que o aluno realizasse a prova.

Com base nos estudos citados, percebe-se que a ausência de motivação do estudante para realizar o exame pode afetar o desempenho alcançado, pois o aluno desmotivado pode ficar descomprometido com o exame, seja por meio do boicote, seja pela falta de empenho na resolução adequada de todas as questões. De qualquer forma, esse comportamento poderá interferir no resultado da avaliação institucional e do curso.

\section{Teoria da Autodeterminação}

Para Robbins (2005), "a motivação é o resultado da interação do indivíduo com a situação" (p.132), pois as pessoas possuem tendências motivacionais básicas diferentes, causadas pela situação. Conceitualmente, a motivação é "o processo responsável pela intensidade, direção e persistência dos esforços de uma pessoa para o alcance de uma determinada meta" (p.132). Na mesma linha de entendimento, Lens, Matos e Vansteenkiste (2008) entendem que motivação se trata de "um processo psicológico no qual interatuam as características da personalidade (por exemplo, motivos, razões, habilidades, interesses, expectativas, perspectiva de futuro) e as características ambientais percebidas" (p.17). Nakamura, Fortunato, Rosa, Marçal, Pereira e Barbosa (2005) entendem que a motivação é considerada um impulso que faz com que as pessoas trabalhem para atingir seus objetivos e persistam até alcançá-los. Ou seja, é um fator que incita a pessoa em direção a algum objetivo e provoca nela um novo ânimo; ela começa a agir para alcançar esse objetivo e também visualizar novos horizontes, novas conquistas.

A motivação é considerada multifacetada, pois varia de acordo com as necessidades, os motivos e os incentivos de cada ser humano. Na área educacional, a motivação é um elemento extremamente importante que poderá sinalizar o êxito, ou não, de um estudante. Guimarães e Boruchovitch (2004) afirmam que um estudante motivado é caracterizado por: envolver-se ativamente no processo de aprendizagem; engajar-se persistir em tarefas desafiadoras; despender esforços, usando as estratégias pertinentes; buscar aumentar e ou criar novas habilidades de compreensão e de domínio; ser entusiasmado e orgulhoso (no sentido de honra) mediante os resultados de seu desempenho. Os resultados positivos conquistados são estímulos para continuar trabalhando para o aperfeiçoamento constante, tanto pessoal quanto do contexto em que se encontra. Por outro lado, Guimarães (2009) afirma que o estudante desmotivado se posicionará passivamente no processo ensino-aprendizagem, demonstrando pouco esforço e baixa persistência ao alcance de suas metas, resultando em insatisfação na realização de tarefas que lhe são impostas e apresentando resultados abaixo do esperado.

As abordagens sociocognitivistas destacam a existência de duas orientações motivacionais: a intrínseca e a extrínseca (Amabile et al., 1994; Harackiewicks \& Elliot, 1993; Mandelink \& Harackiewicz, 1984). Segundo Guimarães (2009), a motivação intrínseca se manifesta no indivíduo quando ele executa determinada tarefa com um fim em si mesma, por interesse e por prazer na execução, ou seja, a atividade é realizada por iniciativa própria, o incentivo já reside na própria execução da atividade, chamada, então, de autotélica. Diferentemente da motivação intrínseca, a extrínseca denota o cumprimento de determinada tarefa por um motivo externo a ela, como: receber recompensas materiais ou sociais, evitar punições ou sentir-se obrigado ou pressionado a desenvolver algo. Para o estudante motivado extrinsecamente, a realização de determinada tarefa torna seu objetivo quando quer obter recompensas externas (Guimarães, 2009). 
O aluno extrinsecamente motivado necessita de estímulos externos para realizar uma tarefa, seja pelas exigências formais como notas, seja por prêmios, recompensas ou até mesmo para evitar repreensões (Guimarães \& Bzuneck, 2008). Já o aluno intrinsecamente motivado sente prazer em estudar, em cumprir as propostas, sem resistências e encara cada nova etapa como um desafio, independentemente de estímulos externos ou recompensas. Nas palavras de Guimarães e Bzuneck (2008), é o estilo perfeito de autodeterminação e reúne em si seus três elementos: i) locus interno (o comportamento tem origem e regulação pessoal); ii) liberdade psicológica (a pessoa tem um comportamento porque ele é coerente com seus interesses, preferências e necessidades); iii) percepção de escolha (flexibilidade nas decisões sobre o que fazer, como ou até a possibilidade de não fazer).

O aprofundamento dos estudos sobre motivação intrínseca e extrínseca deu origem à teoria da Autodeterminação proposta por Ryan e Deci (1985). A referida teoria teve origem nos anos 1970 após o resultado de três investigações diferentes realizadas em laboratórios em diferentes partes do mundo. $\mathrm{Na}$ perspectiva da teoria da Autodeterminação é inerente ao ser humano a predisposição para alcançar um desenvolvimento saudável e a auto-Regulação. Nos estudos preliminares de Ryan e Deci (1985) a motivação era considerada um constructo unitário, apresentando variações apenas em sua quantidade. Com a evolução e amadurecimento dos estudos dos autores, em relação à qualidade da motivação, foi realizada uma distinção entre níveis motivacionais. Para os autores, a motivação depende de um conjunto de variáveis internas e externas ao indivíduo.

Desse modo, motivação intrínseca e extrínseca compõem um mesmo constructo; não são estáticas e nem se excluem; são interdependentes; manifestam-se no indivíduo de acordo com suas predisposições ou estímulos; não são dois polos opostos.

Ryan e Deci (1985) demonstram a configuração dos diferentes níveis motivacionais classificados em três grupos: motivação intrínseca, extrínseca e desmotivação. Esses elementos aparecem de forma integrada, compondo um continuum que fundamenta a teoria da Autodeterminação, conforme a Figura 1.

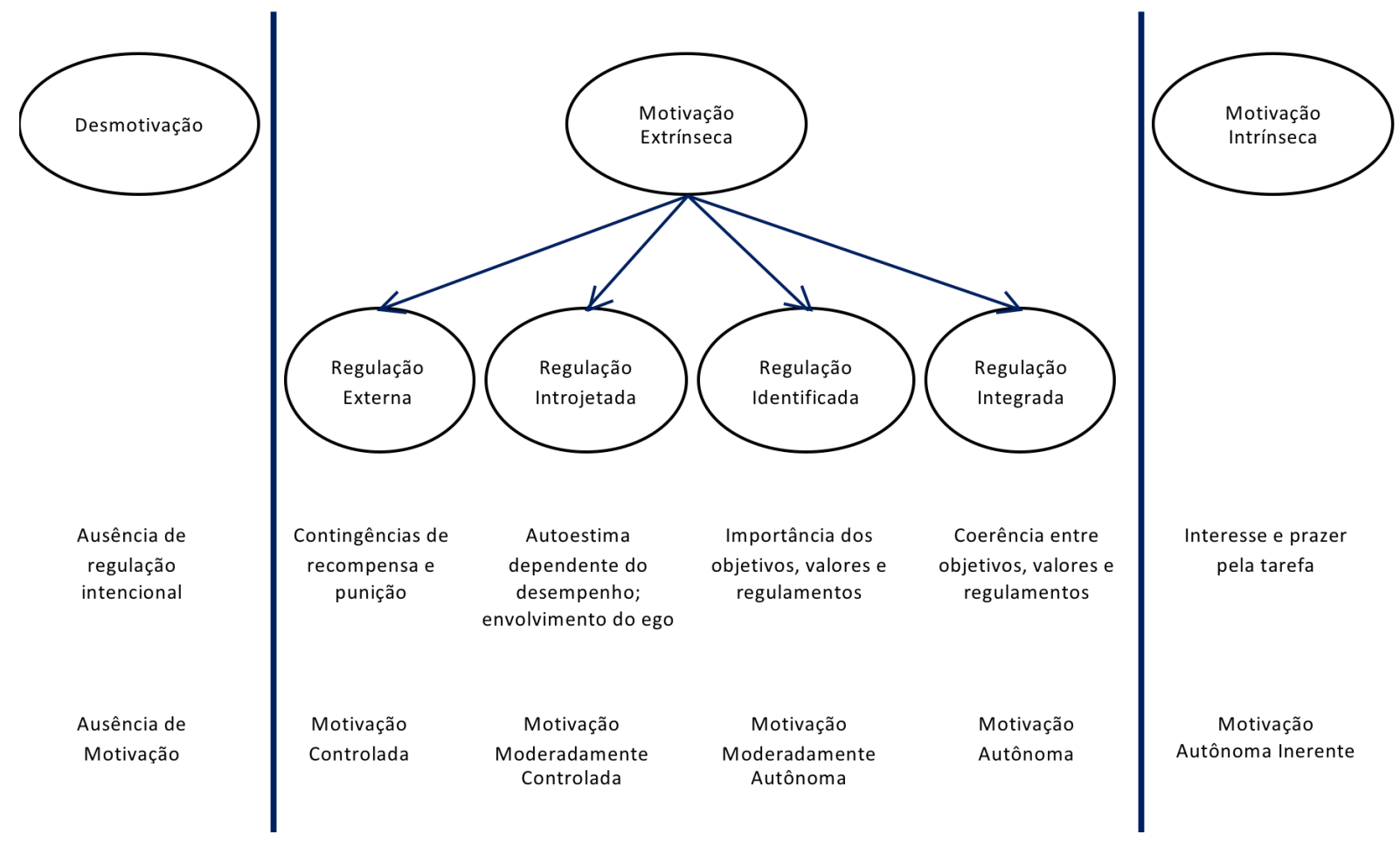

Figura 1. Continuum de Autodeterminação

Fonte: adaptado de Gagné e Deci (2005, p. 336) 
A motivação extrínseca se subdivide em quatro níveis de regulação, que vai desde uma forma puramente externa até uma regulação integrada, próxima à motivação intrínseca. Os autores também afirmam que a motivação intrínseca e as formas autorreguladas da motivação extrínseca dependem da satisfação das três necessidades básicas: competência, autonomia e relacionamento.

Leal, Miranda e Carmo (2013) analisaram estudantes do curso de Ciências Contábeis em relação à motivação à luz da teoria da Autodeterminação. Os estudantes pesquisados apresentaram um perfil de motivação autodeterminada, com a maior média para a motivação intrínseca; em segundo lugar a motivação extrínseca por regulação externa. Foram analisadas as médias de motivação de alunos ingressantes (primeiro ano do curso) e dos alunos concluintes (último ano do curso). Os resultados indicaram que ao iniciarem o curso, os alunos apresentam níveis de motivação autônoma (intrínseca, integrada e identificada) mais elevados e, com o decorrer do tempo, a situação inverte-se, ou seja, os tipos de motivação não autônoma (introjetada, externa e desmotivada) são maiores nos últimos anos do curso. Os autores relataram que os estudantes de Ciências Contábeis pesquisados apresentam indícios de motivação que os direcionam para a obtenção do diploma e das possibilidades por ele proporcionadas, quais sejam, emprego, melhor remuneração, qualidade de vida, prestígio, etc.

Também com base na teoria da Autodeterminação, Coura, Batista, Albuquerque, carvalho e Oliveira (2015) investigaram os tipos de motivação dos estudantes dos cursos de Ciências Contábeis e de Administração da Universidade Federal de Campina Grande. Os resultados evidenciaram que os alunos dos dois cursos investigados se encontram motivados tanto extrínseca quanto intrinsecamente, apresentando maior alinhamento com a motivação "Intrínseca para Saber", seguida pela motivação "Extrínseca Regulação-externa". Os autores não identificaram diferenças significativas entre os cursos e nem relação evidente com o desempenho acadêmico ou com estágio de integralização do curso.

Lopes, Pinheiro, Silva e Abreu (2015) analisaram os fatores motivacionais intrínsecos e extrínsecos característicos aos discentes do curso de Ciências Contábeis em instituições públicas e privadas da Bahia, como também as variáveis propostas pela teoria da Autodeterminação. Não foram evidenciadas diferenças estatisticamente significativas entre a motivação dos alunos de IES públicas e privadas, entretanto verificaram que as mulheres possuem, em média, mais motivação extrínseca por introjeção e motivação intrínseca do que os homens. Já os alunos iniciantes do curso são mais motivados por introjeção e menos desmotivados do que aqueles que estão em fase de conclusão do curso.

\section{Aspectos Metodológicos}

A presente pesquisa tem o propósito de analisar a motivação dos alunos do curso de Ciências Contábeis para a realização do Enade no ano de 2015. Trata-se de uma pesquisa descritiva, com abordagem quantitativa, realizada por meio de um levantamento.

O instrumento de pesquisa foi composto de dois blocos de questões. O primeiro tratava das questões relativas à caracterização dos respondentes, como: gênero, turno e período em curso, faixa etária, ocupação e se participa ou participou de atividades acadêmicas (exemplos: iniciação científica, PET, monitoria, empresa júnior, etc.).

O segundo bloco do questionário estava composto pelas questões relativas à motivação dos estudantes: a) para fazer o curso de Ciências Contábeis; b) para participar do Enem (aos que participaram da avaliação); c) para fazer o Enade em 2015; d) para fazer o Enade mediante a hipótese de uso da nota (para ingresso na pós-graduação, para concursos públicos, para exames de suficiência, para registro no diploma). Nesse bloco, o estudante deveria informar para cada questão seu nível de motivação, em uma escala de zero a dez pontos. A escala era contínua, poderiam ser informadas notas com variações nas casas decimais ou centesimais, por exemplo. Assim, a nota zero significa que o estudante está totalmente desmotivado, enquanto a nota 10 representa o estudante totalmente motivado, e a nota cinco, meio da escala, implica que o estudante não está nem motivado, nem desmotivado, ou seja, indiferente à realização da prova. 
Foi realizado um pré-teste com dez professores das áreas de Administração, Ciências Contábeis e Educação, todos eles pesquisadores das áreas de Educação e/ou de Negócios. Após várias contribuições dos participantes, o instrumento foi finalizado e aplicado.

Por meio da Plataforma E-Mec, foram obtidos os endereços eletrônicos dos cursos de Ciências Contábeis brasileiros. De posse desses contatos, os questionários foram encaminhados aos coordenadores e/ ou diretores dos cursos com a solicitação de que fossem encaminhados aos estudantes. Foram feitos três envios em intervalos de uma semana, com diferentes apelos para a participação dos estudantes, conforme sugerido por Gall, Gall \& Borg (2007).

Como o objetivo da pesquisa é analisar a motivação dos alunos de Ciências Contábeis para a realização do Enade em 2015, a coleta de dados foi realizada nos meses que antecederam o exame - setembro, outubro e novembro de 2015 - e finalizada no dia anterior à aplicação do Enade, ou seja, 21 de novembro. Foram obtidas 1.149 respostas, e, dessas, 67 foram descartadas por estarem incompletas ou porque os respondentes não aceitaram participar da pesquisa, ou ainda por se referirem a alunos de outros cursos. A amostra final, não probabilística, ficou composta de 1.082 respostas.

Por meio do teste Kolmogorov-Smirnof, foi constatado que os dados não possuíam distribuição normal. Assim, para avaliar a existência de diferenças estatísticas referentes à motivação dos estudantes de Ciências Contábeis para a realização do Enade, com e sem oferta de mecanismos de motivação extrínseca, foram utilizados os testes não paramétricos Mann-Whitney e Wilcoxon, os quais tiveram seus pressupostos atendidos.

O teste de Wilcoxon é utilizado para a comparação de médias populacionais em amostras emparelhadas para dar suporte ao nível de significância das possíveis diferenças dos pares (grupos) para as variáveis testadas, considerando a mediana populacional (Fávero, Belfiore, Silva \& Chan, 2009). Assim, o teste foi utilizado para averiguar a diferença dos níveis de motivação dos alunos para a realização do Enem e do Enade (Tabela 3), como também para verificar o nível de motivação para o Enade, com e sem as possibilidades do uso da nota em pós-graduação, concursos, Exame de Suficiência e registro do diploma (Tabela 6). A Tabela 1 apresenta as variáveis utilizadas nos testes.

\section{Tabela 1}

\section{Descrição das variáveis utilizadas nos testes de médias}

\begin{tabular}{|c|c|c|}
\hline Variável & Descrição & Mensuração \\
\hline ENEM & $\begin{array}{l}\text { Refere-se ao nível de motivação que o aluno possuía para } \\
\text { participar do Enem. }\end{array}$ & Contínua, de zero a dez \\
\hline Curso & $\begin{array}{l}\text { Refere-se ao nível de motivação do aluno para realizar o curso de } \\
\text { Ciências Contábeis. }\end{array}$ & Contínua, de zero a dez \\
\hline ENADE 2015 & $\begin{array}{l}\text { Refere-se ao nível de motivação do aluno para participar do Enade } \\
\text { em } 2015 .\end{array}$ & Contínua, de zero a dez \\
\hline ORG-ACAD & $\begin{array}{l}\text { Refere-se à organização acadêmica da instituição a que o } \\
\text { participante da pesquisa está vinculado. }\end{array}$ & $\begin{array}{l}\text { Binária, na qual } 1 \text { corresponde à } \\
\text { instituição pública e } 0 \text { corresponde à } \\
\text { instituição privada }\end{array}$ \\
\hline CAT-ADM & $\begin{array}{l}\text { Refere-se à categoria administrativa da instituição a que o } \\
\text { participante da pesquisa está vinculado. }\end{array}$ & $\begin{array}{l}\text { Binária, na qual } 1 \text { corresponde à } \\
\text { universidade e } 0 \text { corresponde a } \\
\text { faculdades e centros universitários }\end{array}$ \\
\hline Região & $\begin{array}{l}\text { Refere-se à região na qual está situada a instituição a que o } \\
\text { participante da pesquisa está vinculado. }\end{array}$ & $\begin{array}{l}\text { Binária, na qual } 1 \text { corresponde às } \\
\text { regiões Sul e Sudeste e } 0 \text { corresponde às } \\
\text { regiões Norte, Nordeste e Centro-Oeste }\end{array}$ \\
\hline $\begin{array}{l}\text { Pós- } \\
\text { Graduação }\end{array}$ & $\begin{array}{l}\text { Refere-se ao nível de motivação do aluno para participar do Enade } \\
\text { caso a nota fosse utilizada para ingresso na pós-graduação. }\end{array}$ & Contínua, de zero a dez \\
\hline Concursos & $\begin{array}{l}\text { Refere-se ao nível de motivação do aluno para participar do Enade } \\
\text { caso a nota fosse utilizada em concursos públicos. }\end{array}$ & Contínua, de zero a dez \\
\hline Exame CFC & $\begin{array}{l}\text { Refere-se ao nível de motivação do aluno para participar do Enade } \\
\text { caso a nota fosse utilizada no Exame de Suficiência promovido pelo } \\
\text { Conselho Federal de Contabilidade (CFC), }\end{array}$ & Contínua, de zero a dez \\
\hline Diploma & $\begin{array}{l}\text { Refere-se ao nível de motivação do aluno para participar do Enade } \\
\text { caso a nota fosse registrada no verso do diploma, }\end{array}$ & Contínua, de zero a dez \\
\hline
\end{tabular}

Fonte: dados da pesquisa. 
Já o teste de Mann-Whitney foi utilizado para testar duas amostras independentes, envolvendo a organização acadêmica (pública e privada); a categoria administrativa (universidade versus faculdades/ centros universitários); e a região (Sul e Sudeste versus Norte, Nordeste e Centro-Oeste). Ou seja, o teste possibilitou, de forma complementar, verificar a existência, ou não, de diferenças significativas entre os níveis de motivação dos alunos para a realização do Enade.

As hipóteses estatísticas formuladas para serem testadas foram:

- Hipótese nula $\left(\mathrm{H}_{0}\right)$ : não há diferença significativa entre os níveis de motivação dos alunos do curso de Ciências Contábeis para as variáveis e grupos pesquisados.

- Hipótese alternativa $\left(\mathrm{H}_{1}\right)$ : há diferença significativa entre os níveis de motivação dos alunos do curso de Ciências Contábeis para as variáveis e grupos pesquisados.

\section{Análise e Discussão dos Resultados}

A amostra de 1.082 respostas foi composta por estudantes de 122 instituições de ensino brasileiras, sendo $45,3 \%$ de alunos de IES da região Sudeste; $29,2 \%$ do Sul; 9,7\% do Nordeste; 9,2\% do Centro-Oeste e $5 \%$ de estudantes da região Norte. Foi verificado que $73 \%$ dos alunos estudavam em instituições públicas e que $74,1 \%$ estavam vinculados a universidades.

Também foi observado que $61,2 \%$ dos respondentes eram do sexo feminino; $60,2 \%$ possuíam até 25 anos de idade; $84,5 \%$ cursavam do quinto ao décimo período do curso; 79,6\% estudavam no turno noturno; $79,2 \%$ estavam vinculados ao mercado de trabalho; $23,8 \%$ já haviam participado ou participavam de atividades acadêmicas (iniciação científica, programa de ensino tutorial, monitoria ou empresa júnior); e $70,8 \%$ haviam feito o Enem, mesmo que não tivesse sido utilizado para ingresso no curso.

Em síntese, o perfil predominante da amostra era de alunas com até 25 anos de idade, vinculadas ao mercado de trabalho, cursando a segunda metade do curso, no turno noturno, em universidades públicas das regiões Sul e Sudeste e que participaram do Enem.

A Tabela 2 apresenta as medidas de tendência central, média, mediana, moda e desvio -padrão relativas ao nível de motivação dos pesquisados para a realização do Enem, para a realização do curso de Ciências Contábeis e para a realização do Enade em 2015.

Tabela 2

Medidas de tendência central - Motivação para o curso, Enem e Enade 2015

\begin{tabular}{cccccc}
\hline & N & Média & Mediana & Moda & Desvio Padrão \\
\hline ENEM & 815 & 7,231 & 8 & 8 & 2,863 \\
\hline CUrSO & 1065 & 7,710 & 8 & 8 & 2,066 \\
\hline ENADE 2015 & 1074 & 5,818 & 7 & 8 & 3,081 \\
\hline
\end{tabular}

Nota: dados da pesquisa.

De acordo com a Tabela 2, os estudantes apresentaram motivação média em torno de 7,7 pontos para a realização do curso (escala de zero a 10 pontos), um pouco acima da motivação média que eles possuíam para a realização do Enem (7,2 pontos). Os dados revelam também que tanto a média quanto a mediana da motivação para a realização do Enade são menores que a motivação para o Enem. Essa constatação é importante, uma vez que, quando eles fizeram o Enem, poderiam estar motivados a terem bons rendimentos para concorrerem a uma vaga no ensino superior em uma instituição pública ou a bolsas de estudos/financiamentos nas instituições particulares. Todavia, para avaliar se a diferença é significante, foi realizado o teste Wilcoxon, apresentado na Tabela 3. 
Tabela 3

Teste de Medianas - Enem versus Enade 2015

\begin{tabular}{|c|c|c|c|c|}
\hline $\begin{array}{c}\text { Variável } \\
\text { (Motivação) }\end{array}$ & $\mathbf{N}$ & Média dos postos & Estatística Z & P-Valor \\
\hline ENADE $2015<$ ENEM & 404 & 280,41 & \multirow{3}{*}{$-10,081$} & \multirow{3}{*}{0,000} \\
\hline ENADE 2015 > ENEM & 146 & 261,92 & & \\
\hline ENADE 2015 = ENEM & 263 & - & & \\
\hline
\end{tabular}

Nota: dados da pesquisa.

O teste confirma que, de fato, os níveis de motivação dos alunos para a realização do Enade são inferiores à motivação que informaram possuir para fazer o Enem ( $\mathrm{p}$-valor $=0,000)$. Nesse caso, a hipótese nula foi rejeitada, ou seja, existe diferença entre o nível de motivação dos estudantes de Ciências Contábeis para as variáveis Enem e Enade. Os achados reforçam o relato de Guimarães e Bzuneck (2008), que afirmam que alunos extrinsecamente motivados necessitam de estímulos externos para a realização de uma tarefa, como notas, prêmios e recompensas. A esse respeito, Leitão et al. (2010) já apontavam que há falta de incentivos à realização do Enade por parte dos estudantes, ou seja, o uso de recompensas poderá aumentar a motivação e o desempenho dos estudantes, conforme espera o Ministério da Educação (Cameron, 2001).

$\mathrm{Na}$ Tabela 4, é apresentado o teste não paramétrico Mann-Whitney relativo à motivação para o Enade 2015 dos estudantes para as variáveis ORG-ACAD (organização acadêmica), CAT-ADM (categoria administrativa) e região.

Tabela 4

Teste de medianas: análise por instituições

\begin{tabular}{llll}
\hline \multicolumn{1}{c}{ Variáveis } & N & Média dos postos & P-Valor \\
\hline ORG-ACAD & & & \\
\hline \multicolumn{1}{l}{ IES Públicas } & 784 & 513,53 & 0,004 \\
IES Privadas & 284 & 575,18 & \\
\hline CAT-ADM & & & 0,001 \\
\hline $\begin{array}{l}\text { Universidades } \\
\text { Faculdades e Centros } \\
\text { Universitários }\end{array}$ & 795 & 584,17 & \\
\hline Região & 263 & 511,42 & \\
\hline $\begin{array}{l}\text { Sul e Sudeste } \\
\quad \text { Norte, Nordeste e } \\
\text { Centro-Oeste }\end{array}$ & 801 & & 0,015
\end{tabular}

Nota: dados da pesquisa.

Os resultados do teste foram significativos ao nível de $5 \%$ para todos os grupos testados, rejeitando a hipótese nula, ou seja, para os grupos investigados, há diferença significativa entre os níveis de motivação dos alunos do curso de Ciências Contábeis em relação à realização do Enade.

Os alunos das instituições privadas possuem maiores níveis de motivação para o Enade que os alunos de instituições públicas. Como enfatizado por Brito (2008), os indicadores apurados a partir do Enade, na maioria das vezes, são utilizados para alocação de recursos e para promoção da imagem da instituição. Isso pode explicar o fato de as faculdades particulares terem mais ações para sensibilizarem e para motivarem os seus alunos (Silva, Miranda \& Freitas, 2017), fator esse que justifica as médias de motivação dos alunos de instituições privadas serem mais altas do que dos alunos de instituições públicas.

As universidades também apresentaram médias maiores que os centros universitários e faculdades. É importante destacar que os estudantes de universidades também apresentaram notas maiores que os demais nas edições anteriores do Enade, conforme os estudos de Santos (2012) e Ferreira (2015). Também foi 
interessante observar que os alunos das regiões Norte, Nordeste e Centro-Oeste estavam mais motivados que os das regiões Sul e Sudeste para a realização do Enade. Entretanto, as regiões Sul e Sudeste, nas edições anteriores do Enade, apresentaram notas médias maiores que as demais (Santos, 2012; Ferreira, 2015).

As diferenças apresentadas na Tabela 4 encontram respaldo nas palavras de Martinelli e Bartholomeu (2007), os quais estabelecem que a motivação é um fenômeno multifacetado, que varia de acordo com as necessidades, os motivos e os incentivos de cada ser humano.

Por outro lado, Dias Sobrinho (2010) entende que esse exame não só avalia o sistema de ensino superior, mas também acaba por ditar comportamentos dos agentes envolvidos. Nesse sentido, para verificar se a oferta de estímulos aumentaria a motivação para realização do Enade, são apresentadas na Tabela 5 as medidas de tendência central para as percepções dos estudantes diante das possibilidades investigadas.

Tabela 5

Medidas de tendência central - uso do Enade na carreira do estudante

\begin{tabular}{lccccc}
\hline \multicolumn{1}{c}{ Uso da nota Enade em: } & $\mathbf{N}$ & Média & Mediana & Moda & Desvio padrão \\
\hline Pós-Graduação & 1073 & 8,325 & 9 & 10 & 2,357 \\
\hline Concursos & 1074 & 8,919 & 10 & 10 & 2,002 \\
\hline Exame CFC & 1075 & 8,751 & 10 & 10 & 2,080 \\
\hline Diploma & 1072 & 8,100 & 9 & 10 & 2,630 \\
\hline
\end{tabular}

Nota: dados da pesquisa.

Pode-se constatar que as médias e medianas relativas ao uso da nota Enade (pós-graduação, concursos, exame do CFC e diploma - Tabela 5) foram todas numericamente superiores à motivação para a realização do Enade 2015 (Tabela 2). As médias subiram de 5,818 para valores acima de 8 pontos; já a mediana subiu de 7 para 9 em duas situações e $10 \mathrm{em}$ outras duas. Os resultados corroboram o que foi apontado por Leitão et al. (2010) e Pederneiras et al. (2011), ou seja, os alunos não se sentem incentivados/motivados à realização do Enade. Nesse sentido, percebe-se que o aumento de estímulos externos acaba por influenciar positivamente o nível de motivação dos alunos.

Na Tabela 6, por meio do teste Wilcoxon, pode-se visualizar se tais diferenças são significantes.

Tabela 6

Teste de Medianas - Motivação ENADE com e sem possibilidades de uso da nota

\begin{tabular}{|c|c|c|c|c|}
\hline $\begin{array}{c}\text { Variável } \\
\text { (Motivação) }\end{array}$ & $\mathbf{N}$ & $\begin{array}{c}\text { Média dos } \\
\text { postos }\end{array}$ & Estatística Z & P-Valor \\
\hline Pós-graduação < ENADE 2015 & 68 & 259,64 & & \\
\hline Pós-graduação > ENADE 2015 & 782 & 439,92 & $-22,849$ & 0,000 \\
\hline Pós-graduação = ENADE 2015 & 218 & - & & \\
\hline Concursos < ENADE 2015 & 48 & 306,18 & & \\
\hline Concursos > ENADE 2015 & 855 & 460,19 & $-24,206$ & 0,000 \\
\hline Concursos = ENADE 2015 & 166 & - & & \\
\hline Exame CFC < ENADE 2015 & 47 & 250,32 & & \\
\hline Exame CFC > ENADE 2015 & 843 & 456,38 & $-24,364$ & 0,000 \\
\hline Exame CFC = ENADE 2015 & 180 & - & & \\
\hline Diploma < ENADE 2015 & 78 & 310,69 & & \\
\hline Diploma > ENADE 2015 & 752 & 426,37 & $-21,505$ & 0,000 \\
\hline Diploma = ENADE 2015 & 237 & - & & \\
\hline
\end{tabular}

Nota: dados da pesquisa. 
A Tabela 6 deixa evidente que todas as possibilidades de uso da nota Enade elevam o nível de motivação dos estudantes de forma significante ( $\mathrm{p}$-valor $=0,000$ ). Esses resultados permitem rejeitar a hipótese nula proposta para os testes estatísticos, pois existe diferença significativa entre o nível de motivação para as variáveis propostas na realização do Enade, envolvendo o uso, ou não, da nota para pós-graduação, concursos, exame do CFC e registro do diploma.

Cabe lembrar, ainda, que o aumento na motivação poderá trazer efeitos positivos também no desempenho dos estudantes que buscam obter recompensas externas (Cameron, 2001; Guimarães, 2009). Cameron (2001) defende que tarefas que despertam pouco interesse aos estudantes devem receber incentivos para sua realização. Assim, é possível que a introdução do uso da nota do Enade para ingresso em cursos de pós-graduação e seu registro no diploma - como propôs o ministro da Educação, em 2015 (Cazarré, 2015) - possam incentivar os alunos e, consequentemente, elevar as notas médias de maneira geral.

A Tabela 7 apresenta a síntese do teste não paramétrico Mann-Whitney relativa à motivação dos estudantes por: organização acadêmica; categoria administrativa e região na hipótese de registro da nota Enade no diploma e seu uso para ingresso na pós-graduação, em concursos e no exame do CFC.

Tabela 7

teste de Medianas - P-Valor das motivações relativas ao uso da nota Enade

\begin{tabular}{ccccc}
\hline \multicolumn{1}{c}{ Variáveis } & Pós-graduação & Concursos & Exame CFC & Diploma \\
\hline $\begin{array}{l}\text { Organização Acadêmica } \\
\text { IES Públicas } \\
\text { IES Privadas }\end{array}$ & 0,021 & 0,534 & 0,264 & 0,178 \\
\hline Categoria Administrativa & & & & 0,127 \\
\hline $\begin{array}{l}\text { Universidades } \\
\text { Fac. /C. Univer. }\end{array}$ & 0,008 & 0,701 & $\mathbf{0 , 0 3 6}$ & 0,676 \\
\hline $\begin{array}{l}\text { Região } \\
\text { Sul e Sudeste } \\
\text { NO, NE e CO }\end{array}$ & 0,021 & 0,512 & 0,554 & \\
\hline
\end{tabular}

Fonte: dados da pesquisa.

É importante lembrar que os níveis de motivação dos alunos para a realização do Enade 2015 eram distintos estatisticamente, por organização acadêmica, por categoria administrativa e por região (Tabela 4). No entanto, ao serem oferecidas possibilidades de uso da nota em situações futuras, essa diferença tende a desaparecer, ou seja, a motivação deixa de ser uma variável que se diferencia conforme organização acadêmica, categoria administrativa ou região. Em outras palavras, as diferenças aparecem de forma consistente apenas no tocante ao uso da nota para ingresso na pós-graduação, o que é razoável uma vez que apenas um percentual pequeno de estudantes se encaminha para a pós-graduação.

Isso significa que o uso desses estímulos motivacionais contribuiria para tornar os resultados do Enade mais acurados, pois os alunos estariam mais interessados em realizar a prova. Em outras palavras, a variável motivação afetaria menos as divergências de desempenho entre os estudantes. O nível de motivação dos estudantes de Ciências Contábeis para a realização do Enade com o estímulo de recompensas, caso efetivado, poderá refletir em sua postura ao realizar a prova e, consequentemente, envolvê-los ativamente no processo de aprendizagem, traduzindo resultados mais confiáveis e mais próximos da realidade concreta, minorando as possibilidades dos "boicotes" (Guimarães \& Boruchovith, 2004).

Por fim, foi questionado aos alunos se a participação nesta pesquisa poderia, de alguma forma, influenciar seus níveis de motivação para a realização do Enade 2015. Verificou-se que $23,1 \%$ dos participantes não responderam a essa questão. Das respostas válidas, 30,7\% admitiram que sim, pois a pesquisa despertou possibilidades que eles não haviam imaginado que poderiam ocorrer. 


\section{Considerações Finais}

O objetivo do presente estudo foi identificar os níveis de motivação dos estudantes do curso de Ciências Contábeis para a realização do Enade com e sem a oferta de mecanismos de motivação extrínseca.

Os resultados evidenciaram que os níveis de motivação dos alunos para fazerem o Enade 2015 são estatisticamente inferiores à motivação que eles têm para fazer o curso de Ciências Contábeis e também inferiores à motivação que eles possuíam quando fizeram o Enem. A motivação ainda é menor nas instituições públicas das regiões Sul e Sudeste.

Os resultados também apontaram que a oferta de estímulos como recompensa para esses estudantes, sejam eles registro da nota no diploma, uso da nota para ingresso em pós-graduação, uso da nota para concursos públicos ou para o exame do CFC, afeta positivamente a intenção (motivação) para a realização do Enade.

Esses resultados reafirmam que o uso de incentivos e/ou recompensas pode aumentar a motivação e o desempenho quando são oferecidos sob condições apropriadas (Cameron, 2001). Entretanto, é importante reconhecer a importância da motivação intrínseca no processo de aprendizagem, conforme sugerido na teoria de avaliação cognitiva. As recompensas são oferecidas como incentivos para comportamentos que não surgem de modo espontâneo, neste caso, tais recompensas são percebidas como controle do comportamento e podem afetar e/ou diminuir a motivação intrínseca. A adoção de incentivos deve ser cuidadosamente ponderada, não restringindo em motivar os estudantes por meio de recompensas, mas promover situações educativas que estimulem a motivação intrínseca (Guimarães, 2009).

O anúncio feito pelo ministro da educação no final do ano 2015, referente à inserção da nota Enade no currículo do estudante e seu uso para ingresso em cursos de pós-graduação, de acordo com os resultados apurados na presente pesquisa, se efetuada, poderia elevar os níveis de motivação extrínseca dos estudantes. Consequentemente, poderiam se tornar mais homogêneos os níveis de motivação entre diferentes regiões e instituições de ensino públicas/privadas ou universidades/faculdades e centros universitários. Ao homogeneizar os níveis de motivação para a prova, poderia haver também aumento nas notas médias das instituições em virtude da ausência de boicotes. Enfim, o sistema de avaliação também se tornaria mais acurado no tocante aos propósitos avaliativos.

Os resultados desta pesquisa sinalizam, portanto, novas possibilidades para aperfeiçoamento do sistema de avaliação vigente (Sinaes), tendo em vista que todo e qualquer instrumento de avaliação necessita de se adequar e de acompanhar a complexa e dinâmica evolução pela qual a sociedade passa. Essa possibilidade de "aprimoramento" do Enade, um dos eixos avaliativos do Sinaes, poderá, além de apresentar um modelo que reflita resultados mais fidedignos da realidade do ensino superior brasileiro, contribuir para a qualidade do ensino, já que haverá estímulo concreto não só para a realização do Enade, como também poderá levar ao "despertar" de uma "preocupação" dos estudantes em fazerem um curso bem feito, para realizarem uma boa prova e alcançarem o que os motivou (currículo, ingresso na pós-graduação, etc.). Esses estímulos podem criar um "efeito cascata", no sentido de que, ao se sentirem motivados por um fim, alçarem vários pontos positivos no decorrer dessa trajetória.

As contribuições do presente estudo abarcam a evidenciação do nível de motivação extrínseca dos estudantes de graduação do curso de Ciências Contábeis para a realização de um exame de avaliação de desempenho estudantil com o oferecimento de incentivos. Tais resultados servem como alerta aos gestores públicos ligados à educação sobre a relevância da inserção de reforços e fatores motivacionais externos que poderão contribuir para o envolvimento dos estudantes no processo de aprendizagem. Além disso, os próprios alunos participantes da pesquisa também podem ser beneficiados, uma vez que essa pesquisa antecedeu à realização do exame e quase um terço dos respondentes admitiram que sua participação na pesquisa poderia alterar positivamente sua motivação para o ENADE 2015. 
É importante destacar que no presente estudo foi utilizada a amostra não probabilística, exclusivamente com alunos de Ciências Contábeis, o que não permite a generalização dos resultados, constituindo-se, assim, uma limitação. Todavia, esse aspecto não restringe a relevância dos achados evidenciados na pesquisa, que poderão servir de comparação com outros estudos. Para futuras pesquisas, sugere-se comparar o nível de motivação dos estudantes participantes da pesquisa e o desempenho das IES nas quais esses estudantes estão inseridos, bem como a replicação do estudo em outras áreas.

\section{Referências}

Amabile, T. M., Hill, K. G., Hennessey, B. A. \& Tighe, E. M. (1994). The work preference inventory: Assessing intrinsic and extrinsic motivation orientation. Journal of Personality and Social Psychology, 6(5), pp. 950-967.

Borges, L. F. M., Silva, V. R. \& Miranda, G. J. (2015). Por que o conceito caiu? Fatores associados à nota ENADE/2012 do curso de Ciências Contábeis da Universidade Federal de Uberlândia. Anais do Congresso UFU de Contabilidade. Uberlândia. Uberlândia, MG, Brasil, 1. Recuperado em 04 de março, de: http://www.cont.facic.ufu.br/sites/cont.facic.ufu.br/files/5-3161_por_que_o_conceito_caiu.pdf.

Brito, M. R. F. (2008, november). O SINAES e o ENADE: da concepção à implantação. Revista Avaliação, Campinas, Sorocaba, 13(3), pp. 841-850.

Brito, T. F. (2015). Corpo Docente: fatores determinantes do desempenho discente no ENADE. Dissertação de Mestrado em Ciências Contábeis, Universidade de São Paulo, São Paulo, SP, Brasil.

Cameron, J. (2001). Negative effects of reward on intrinsic motivation - a limited phenomenon: comment on Deci, Koestner, and Ryan (2001). Review of Educational Research, Washington, 71(1), pp. 2942. doi/abs/10.3102/00346543071001029

Cazarré, M. (2015). Nota do Enade será critério para acesso do aluno à pós-graduação, diz Mercadante. Agência Brasil. Recuperado em 04 de março, de: http://agenciabrasil.ebc.com.br/educacao/ noticia/2015-12/nota-no-enade-sera-criterio-para-acesso-pos-graduacao-diz-mercadante.

Coura, E.A.A., Batista, F.F., Albuquerque, L.S., Cime, G.M.P., Carvalho, J.R.C. \& Oliveira, F.D.C. (2015). Análise da Motivação dos Discentes do Curso de Ciências Contábeis e Administração sob a Perspectiva da Teoria da Autodeterminação e das Metas de Realização. Anais do Encontro de Ensino e Pesquisa em Administração e Contabilidade, EnEPQ, Salvador, BA, Brasil, 5.

Dias Sobrinho, J. (2008). Qualidade, Avaliação: do SINAES a índices. Revista da Avaliação da Educação Superior, Campinas, Sorocaba, 13(3), pp. 817-825.

Dias Sobrinho, J. (2010). Avaliação e transformações da educação superior brasileira (1995-2009): do provão ao SINAES. Revista da Avaliação da Educação Superior, Campinas, Sorocaba, 15(1), pp. 195-224.

Fávero, L. P., Belfiore, P. P., Silva, F. L. da \& Chan, B. L. (2009). Análise de dados: modelagem multivariada para tomada de decisões. Rio de Janeiro: Elsevier

Ferreira, M. A. (2015) Determinantes do desempenho discente no ENADE em cursos de Ciências Contábeis. Dissertação de Mestrado em Ciências Contábeis, Universidade Federal de Uberlândia. Uberlândia, MG, Brasil.

Francisco, T. H. A., Melo, P. A., Nunes, R. S. \& Michels, E. (2012). A contribuição da avaliação in loco como fator de consolidação dos princípios estruturantes do SINAES. Avaliação, Campinas, Sorocaba, 17(3), pp. 851-876. 
Freitas, S. C. \& Cornacchione, E. (2015) O uso de resultados de avaliação de programas educacionais: um estudo sobre o ENADE em cursos de Ciências Contábeis. Afonso, L. E.; Machado, E. A. Tecnologia, Educação e Contabilidade. São Paulo: Atlas.

Gall, M. D., Gall, J. P. \& Borg, W. R. (2007). Educational Research: an introduction. 8th. Boston: Pearson/ Allyn and Bacon.

Gagné, M. \& Deci, E. L. (2005, January). Self-determination theory and work motivation. Journal of Organizational Behavior, Malden, 26, pp. 331-362. doi: 10.1002/job.322.

Guimarães, S. E. R. (2009). Motivação intrínseca, extrínseca e o uso de recompensas externas em sala de aula. In E. Boruchovitch, \& J. A. Bzuneck (Orgs.), A motivação do aluno: contribuições da psicologia contemporânea. (pp. 37-57). Petrópolis: Vozes.

Guimarães, S. E. R. \& Boruchovitch, E. (2004). O Estilo Motivacional do Professor e a Motivação Intrínseca dos Estudantes: Uma Perspectiva da Teoria da Autodeterminação. Psicologia: Reflexão e Crítica, 17(2), pp. 143-150.

Guimarães, S. E. R. \& Bzuneck, J. A. (2008) Propriedades psicométricas de um instrumento para avaliação da motivação de universitários. Ciências \& Cognição, Rio de Janeiro, 13(1), pp. 101-113.

Hanushek, E. A. (2002). Publicy provide education. In Auerbach, A.J.; Feldstein, M. (Eds.). Handbook of public economics. Stanford: Elsevier, 4, pp. 2045-2141.

Harackiewicks, J. M. \& Elliot, A. J. (1993). Achievement goals and intrinsic motivation.Journal of Personality and Social Psychology, 65(5), pp. 904-915.

Instituto Nacional de Estudos e Pesquisas Educacionais Anísio Teixeira (2016). Sinaes. Recupedo em 04 de março, de http://portal.inep.gov.br/web/guest/superior-sinaes.

Leal, E. A., Miranda, G. J. \& Carmo, C. R. S. (2013, August) Teoria da autodeterminação: uma análise da motivação dos estudantes do curso de ciências contábeis. Revista Contabilidade \& Finanças, 24(62), pp. 162-173. Recuperado em 04 de março, de: <http://www.revistas.usp.br/rcf/article/view/78828>. doi:http://dx.doi.org/10.1590/S1519-70772013000200007.

Leitão, T. M. S. P., Moriconi, G. M., Abrão, M. \& Silva, D. S. (2010). Análise acerca do boicote dos estudantes aos exames de avaliação do ensino superior. Estudos em Avaliação Educacional, 21(45), pp. 87-106. doi.org/10.1590/S1413-24782010000100003

Lens, W., Matos, L. \& Vansteenkiste, M. (2008). Professores como fontes de motivação dos alunos: o quê e o porquê da aprendizagem do aluno. Educação, Porto Alegre, 31 (1), pp. 17-10.

Lopes, L.M.S., Pinheiro, F.M.G., Silva, A.C.R. \& Abreu, E.S. (2015). Aspectos da Motivação Intrínseca e Extrínseca: uma análise com discentes de Ciências Contábeis da Bahia na perspectiva da Teoria da Autoderminação. Revista de Gestão, Finanças e Contabilidade, UNEB, Salvador, 5(1), pp. 21-39.

Mandelink, G. \& Harackiewicz, J. (1984). Proximal versus distal goal setting and intrinsic motivation. Journal of Personality and Social Psychology, 47(4), pp. 918-928.

Martinelli, S. C. \& Bartholomeu, D. (2007). Escola de Motivação Acadêmica: uma medida de motivação extrínseca e intrínseca. Avaliação Psicológica, 6(1), pp. 21-31.

Nakamura, C. C., Fortunato, J. C., Rosa, L. M., Marçal, R., Pereira, T. A. A. \& Barbosa, D. F. (2005). Motivação no trabalho. Maringá Management: Revista de Ciências Empresariais, 2(1), pp. 20-25.

Organization for Economic Co-operation and Development (2015). Education at a Glance 2015: OECD indicators. Recuperado em 04 de março, de: http://www.oecd-ilibrary.org/docserver/ download/9615031e.pdf?expires $=1450782870 \& \mathrm{rid}=\mathrm{id} \&$ accname $=$ guest $\&$ checksum $=45 \mathrm{~F} 28 \mathrm{~F} 5521$ A380A35ADA67A270BEE066. 
Pederneiras, M. M. M., Lopes, J. E. de G., Ribeiro Filho, J. F. \& Feitosa, M. G. G. (2011) Exame nacional de desempenho dos estudantes na visão de líderes formais. Revista Ensaio: aval. pol. públ. Educ., Rio de Janeiro, 19(71), pp. 381-400.

Polidoro, M. M, Marinho-Araujo, C. M. \& Barreyro, G. B. (2006). SINAES: Perspectivas e desafios na avaliação da educação superior brasileira. Revista Ensaio: aval. Pol. Pbl. Educ., Rio de Janeiro, 14(53), pp. 425-436.

Robbins, S. P. (2005) Comportamento Organizacional. 11th ed. São Paulo: Pearson Prentice Hall.

Ryan, R. M. \& Deci, E. L. (1985) Intrinsic and extrinsic motivations: classic definitions and new directions. Contemporary Educational Psychology, New York, 25(1), pp.54-67.

Santos, N. A. (2012). Determinantes do desempenho acadêmico dos alunos dos cursos de Ciências Contábeis. Tese de Doutorado em Ciências Contábeis, Universidade de São Paulo. São Paulo, SP, Brasil.

Silva, T. D., Miranda , G. J. \& Freitas, S. C. (2017). Ações Institucionais Preparatórias para o ENADE nos Cursos de Ciências Contábeis. Revista 